\title{
Demand characteristics and the response suppression hypothesis
}

\author{
PAUL S. SIEGEL, EDWARD A. KONARSKI, and SCOTT L. BERNARD \\ University of Alabama, University, Alabama
}

\begin{abstract}
College student subjects were given the opportunity to pull a plunger (Linsley manipulandum) or press a small panel in a three-stage design. Five minutes of free access (baseline) was followed by a 5-min contingency phase in which 10 responses to the plunger were required to free the panel for a single press. This was followed by a 5-min return to baseline. From a postexperiment questionnaire, subjects were judged to have been either aware or unaware of the contingent relation between the plunger and the panel. Those judged to have been aware yielded much higher rates of plunger pulling during the contingent phase and were more active during baseline measurement. These results raise problems for the response suppression methodology of Eisenberger, Karpman, and Trattner (1967), since they can be as readily accounted for by Orne's (1962) demand hypothesis.
\end{abstract}

In 1959, Premack gave us a unique interpretation of the Law of Effect. He viewed the reinforcement process as an arrangement between two responses such that when the more probable was made contingent upon the less probable, the less probable one, now instrumental, would increase in strength. He fully developed the implications of this hypothesis in later work (Premack, 1963, 1965, 1971). In 1967, Eisenberger, Karpman, and Trattner gave emphasis to a different notion of reinforcement. They argued that the reinforcement effect would occur only if the schedule requirements made it impossible to realize the free operant level of the contingent response without increasing the level of instrumental responding. Thus, relative "suppression" of the contingent response was taken to be crucial. Parenthetically, it should be noted here that Premack did not ignore the contribution made by the schedule requirements, but nonetheless clung to probability differential as the key to reinforcement.

Eisenberger et al. (1967) offered as supporting evidence data obtained from adult student subjects who had been provided opportunity to manipulate several rather simple manipulanda. Specifically, subjects were told they could turn a small wheel, pull a plunger, press a bar or a lever, or do nothing, as they wished. And in a series of studies, the investigators arranged various contingent relations between two of these responses. It is not the purpose of the present paper to challenge the theory of "response suppression." Indeed it appears to us that in its more recent, more mature forms (Timberlake, 1980; Timberlake \& Allison, 1974), the theory is prospering. We should like to suggest, however, that the outcome of the Eisenberger et al. studies may be as readily interpreted as resulting from "demand characteristics" (Orne, 1962) as from the objectively defined schedule arrangements. Surely, student subjects confronted with the task of play-

Reprint requests should be addressed to Paul S. Siegel, Department of Psychology, Box 2968, University, AL 35486. ing or not playing with trivial, toy-like manipulanda (turning a little wheel, pressing a little bar or lever, or pulling a knob) must seek "meaning" in the situation. Furthermore, it seems highly likely that the student's quest for meaning might take the form: "What is expected of me?" or "What does the experimenter want me to do?" And having discovered a plausible answer, student subjects are likely to act accordingly. Although other subject attitudes or roles have been identified (cf. Carlston \& Cohen, 1980; Kruglanski, 1975; Weber \& Cook, 1972), it has been our experience that most college student subjects act to confirm their interpretation of the investigator's purpose (i.e., they do what they think the investigator wants them to do, so that they are "good subjects"; Orne, 1962). If this is the case, the Eisenberger et al. results could be interpreted as resulting from the subjects' perception of the demands of the situation rather than from the objective conditions (schedule requirements) specified by the investigator. This is essentially the general message delivered by Orne in 1962 . We have elected to focus on this issue in the Eisenberger et al. study because of its continuing prominent role in discussions of the approach to reinforcement developed by Premack.

The present paper focuses on the fourth and crucial experiment reported by Eisenberger et al. (1967). In brief, high school students enrolled in a special college course were confronted with a choice between manipulating a small lever, pulling a knob, or doing nothing. Following a 5-min operant period, a contingency was arranged such that the first press of the lever locked it, and for the next $5 \mathrm{~min}$ a fixed ratio that required $10 \mathrm{knob}$ pulls to unlock the lever was in effect. This served to free the lever for a single press. This stage was followed by a return to 5 min of free access to both manipulanda. Those subjects who qualified for analysis (more knob pulling than lever pressing during the initial phase) yielded an increase in knob pulling (the instrumental response) when the contingent relation was arranged. Eisenberger et al. have ar- 
gued that this finding supports their "response suppression" hypothesis, since a weaker response (lever pressing), arranged as a contingency, reinforced a stronger response (knob pulling) when the schedule deprived the subject of the operant level of the weaker response (lever pressing). Whereas this interpretation may well be valid, there is an alternative: Perhaps the subjects yielded this outcome because they perceived certain ongoing events as signals inviting increased knob pulling, and being "good" subjects, they cooperated (Orne, 1962). Our study adds a postexperiment questionnaire designed to discover the subjects' interpretations of the purpose of the experiment. It is not specifically our purpose to examine "response suppression." Rather, we wish to take a look at the possible influence of "cognitions" arising out of the human subject's sensitivity to the demands exercised by this kind of procedure and apparatus.

\section{METHOD}

\section{Subjects}

The experiment was conducted as two replications (Ns of 21 and 15). Subjects were recruited from elementary psychology classes and awarded a small bonus of extra course credit for participation. Approximately half of the subjects were male, and participation was voluntary.

\section{Apparatus and Procedure}

Our procedure and instructions followed closely those of Eisenberger et al. (1967). The subject was confronted with a sloping $(25 \times 70 \mathrm{~cm})$ console that presented opportunity to pull a brass plunger (Lindsley manipulandum) or press a small hinged and spring-loaded panel $(4 \times 16.5 \mathrm{~cm})$. The subject was instructed to remain in his $/$ her seat but otherwise was given freedom to pull the plunger, to press the panel, or to simply do nothing. The 15-min session consisted of $5 \mathrm{~min}$ of free access to both manipulanda, followed by $5 \mathrm{~min}$ of a 10-to- 1 fixed-ratio, contingent relationship between the plunger (instrumental response) and the panel (contingent relation). Ten plunger pulls freed the panel for a single response. The locking and unlocking of the panel was both auditorily and visually quite evident. This phase was followed by a 5-min return to baseline (free access). The postexperiment questionnaire was then administered, and the subject was dismissed. The two replications differed only in the form of the postexperiment questionnaire. In the first replication, open-ended questions were used, and the subject was requested to respond fully in writing. The four crucial questions were: (1) What was the purpose of this experiment? (2) What did you think was happening when the panel locked? (3) Did you feel obligated to do something when the panel locked? What? (4) Do you think you figured it out?

in the second replication, the subject was asked to check one or more of several alternative answers to very similar questions, the alternatives being taken from the most frequent open-ended responses yielded during the first replication ${ }^{1}$. As an example, with instructions to check the "best"' answer, the following alternatives were presented under Question 3 above: (1) No. Not really. (2) No. But I expected something to happen. (3) Yes. I thought I was supposed to do something to unlock it. (4) Yes. I thought I was supposed to pull the knob. (5) Yes. I thought I was supposed to push the panel again. (6) Some other reason (write it down below).

\section{RESULTS AND DISCUSSION}

A preliminary analysis of the results revealed no gender differences, and so this variable was collapsed.

Both sets of questionnaires were judged by a panel of three advanced clinical graduate students acting indepen- dently and without knowledge of the purpose of the experiment or the behavioral findings. They simply decided whether or not the subject's answers exhibited convincing evidence of having discovered the contingent relation between plunger pulling and panel pressing. These subjects were identified as "aware." Alternatively, the subject was judged to be "unaware" if his/her responses strongly suggested failure to discover the contingent relationship. For example, in Replication 1, to the question "Did you feel obligated to do something when the panel locked?" the aware subject may have responded "Yes, pull the knob." Or, in response to the above question from Replication 2, the aware subject may have checked the alternative "Yes. I thought I was supposed to pull the knob." Subjects whose answers yielded no indication of awareness were judged to be unaware.

The judges also rated their own confidence in each judgment. This was done on a 1-to-5 scale (from no confidence to extremely confident). Confidence was uniformly high for the 31 cases designated for analysis, with all three judges checking a 4 or a 5 on the confidence scale.

The data analyzed in the present paper were taken from the records yielded by subjects on whom the three judges agreed unanimously. Of the 21 subjects tested in Replication 1, there were 18 such subjects. From Replication 2, 13 of 15 subjects qualified. One subject was lost from each replication through failure to yield even a single manipulatory response. The remaining discards $(n=3)$ were those yielding records on which the judges disagreed. Since the two replications differed only in the form of the questionnaire and since all subjects were drawn from a common population, the results of the two were combined, and final analysis was based on a total of 31 cases.

Table 1 presents our results. On top are the records yielded by subjects judged unanimously to have become aware of the relationship between the plunger and the locked panel. Those judged unanimously to have been unaware of the relationship are presented in the lower portion of the table.

Attesting to high intrasubject reliability, panel pressing and plunger pulling during the first baseline correlated .958 for the aware group and .968 for the unaware group. Plunger pulling during the two baselines correlated .783 for the aware group and .883 for the unaware group. Plunger pulling for the aware group during the contingency phase correlated .902 with plunger pulling during the first baseline period and .874 with the second baseline; for the unaware group, these values were found to be .986 and .886 , respectively.

In Table 1, two group differences are immediately obvious: First, the aware subjects were more active during the initial baseline. Means and SDs for plunger pulling by the two groups are shown in Table 1 . For the aware group; the mean panel pressing was $72.7 \pm 78.90$; for the unaware group, 24.2 \pm 46.31 . By Mann-Whitney $U$ Test (Siegel, 1956), the difference between groups was found to be statistically reliable (two-tailed test) for both plunger pulling $(U=46, p<.02)$ and panel pressing 
Table 1

Frequency of Responding (Plunger Pulls) by Aware and Unaware Groups During Baseline and Contingent Phases

\begin{tabular}{|c|c|c|c|c|}
\hline & $\begin{array}{c}\text { Initial } \\
\text { Baseline }\end{array}$ & $\begin{array}{c}\text { Contingent } \\
\text { Phase }\end{array}$ & $\begin{array}{c}\text { Proportion } \\
\text { Change }\end{array}$ & $\begin{array}{c}\text { Second } \\
\text { Baseline }\end{array}$ \\
\hline \multicolumn{5}{|c|}{ Aware Group $(N=18)$} \\
\hline & $\begin{array}{r}22 \\
255 \\
99 \\
8 \\
140 \\
8 \\
12 \\
271 \\
122 \\
14 \\
49 \\
74 \\
6 \\
56 \\
22 \\
15 \\
22 \\
10\end{array}$ & $\begin{array}{r}162 \\
532 \\
312 \\
48 \\
285 \\
84 \\
184 \\
873 \\
117 \\
39 \\
78 \\
112 \\
8 \\
235 \\
86 \\
101 \\
36 \\
23\end{array}$ & $\begin{array}{r}7.36 \\
2.09 \\
3.15 \\
6.00 \\
2.04 \\
10.50 \\
15.33 \\
3.22 \\
.96 \\
2.79 \\
1.59 \\
1.51 \\
1.33 \\
4.20 \\
3.91 \\
6.73 \\
1.64 \\
2.30\end{array}$ & $\begin{array}{r}159 \\
294 \\
48 \\
26 \\
56 \\
12 \\
31 \\
363 \\
32 \\
9 \\
8 \\
58 \\
4 \\
167 \\
136 \\
21 \\
21 \\
28\end{array}$ \\
\hline $\begin{array}{l}\text { Mean } \\
S D\end{array}$ & $\begin{array}{l}66.90 \\
82.38\end{array}$ & $\begin{array}{l}184.20 \\
215.74\end{array}$ & $\begin{array}{l}4.26 \\
3.75\end{array}$ & $\begin{array}{r}81.80 \\
103.69\end{array}$ \\
\hline \multicolumn{5}{|c|}{ Unaware Group $(N=13)$} \\
\hline & $\begin{array}{r}15 \\
1 \\
5 \\
11 \\
2 \\
8 \\
152 \\
3 \\
2 \\
1 \\
25 \\
7 \\
16\end{array}$ & $\begin{array}{r}8 \\
0 \\
2 \\
1 \\
0 \\
29 \\
326 \\
29 \\
3 \\
3 \\
21 \\
5 \\
25\end{array}$ & $\begin{array}{r}.53 \\
.00 \\
.40 \\
.09 \\
.00 \\
3.63 \\
2.14 \\
9.67 \\
1.50 \\
3.00 \\
.84 \\
.71 \\
1.56\end{array}$ & $\begin{array}{r}7 \\
0 \\
3 \\
0 \\
0 \\
1 \\
23 \\
8 \\
2 . \\
3 \\
5 \\
7 \\
9\end{array}$ \\
\hline $\begin{array}{l}\text { Mean } \\
S D\end{array}$ & $\begin{array}{l}19.1 \\
40.58\end{array}$ & $\begin{array}{l}34.8 \\
88.23\end{array}$ & $\begin{array}{l}1.85 \\
2.61\end{array}$ & $\begin{array}{l}5.2 \\
6.22\end{array}$ \\
\hline
\end{tabular}

$(U=24, p<.01)$. The significance of this finding is not immediately obvious to us. Perhaps these subjects felt that action was demanded. Our postexperiment questionnaire did not explore this possibility.

Of greater interest, our aware subjects exhibited more plunger pulling (instrumental responses) during the contingent phase. Two statistical tests were conducted to evaluate this difference: (1) The change in the frequency of plunger pulling during the contingency phase, relative to the frequency observed during the first baseline phase, was determined for each group and is shown as Column 3 in Table 1. By Mann-Whitney $U$ Test, the two distributions differed reliably $(U=48, p<.02)$. (2) The same analysis applied to proportion change relative to the mean of the two baseline values (ABA order) also yielded a significant Mann-Whitney $U(U=62, p<.05)$. Again, the mean proportion change for the aware group (3.09 \pm $2.227)$ exceeded that of the unaware group $(1.87 \pm$
1.817). These analyses suggest quite strongly that the frequency of plunger pulling was reliably greater during the contingent phase in those subjects who gave evidence of awareness of the contingent relationship between the two responses.

It is of course true that these data establish little more than a correlation. Certainly, we have not demonstrated that the subjects' awareness acted in a causal sense to produce increased plunger pulling. Indeed, we have presented no evidence that the relevant cognition actually preceded in time the relevant action: The aware subjects may have discovered the hypothesis as a consequence of contingent plunger pulling, or perhaps it was suggested by the questionnaire. Furthermore, although the relevant cognition may be a necessary condition, it is not sufficient: The subjects must also put it into action. Kruglanski (1975, pp. 125-130) has presented an incisive analysis of the problems and uncertainties involved in the use of postexperimental questionnaires to arrive at demand interpretations of behavioral data. Brewer (1974), on the other hand, has argued eloquently for awareness as a necessary condition to achieve both operant and classical conditioning in the human subject.

It is our conclusion that the Eisenberger et al. (1967) results may be readily interpreted as a product of demand. Furthermore, it would seem reasonable to claim that our findings would apply no less strongly to other studies using similar procedures with adult human subjects.

\section{REFERENCES}

Brewer, W. F. (1974). There is no convincing evidence for operant and classical conditioning in humans. In W. B. Weimer \& D. S. Palermo (Eds.), Cognition and symbolic processes. Hillsdale, NJ: Erlbaum.

Carlston, D. E., \& Cohen, J. L. (1980). A closer examination of subject roles. Journal of Personality \& Social Psychology, 38, 857-870.

Eisenberger, R., KARPMAN, M., \& TratTNER, J. (1967). What is the necessary and sufficient condition for reinforcement in the contingency situation? Journal of Experimental Psychology, 74, 342-350.

KRUglANSKI, A. (1975). The human subject in the psychological experiment: Fact and artifact. In L. Berkowitz (Ed.), Advances in experimental social psychology (Vol. 8, pp. 101-147). New York: Academic Press.

ORNE, M. T. (1962). On the social psychology of the psychological experiment: With particular reference to demand characteristics and their implications. American Psychologist, 17, 776-783.

Premack, D. (1959). Toward empirical behavior laws: I. Positive reinforcement. Psychological Review, 66, 219-233.

PremaCK, D. (1963). Rate differential reinforcement in monkey manipulation. Journal of the Experimental Analysis of Behavior, 6, 81-89.

Premack, D. (1965). Reinforcement theory. In D. Levine (Ed.), Nebraska symposium on motivation. Lincoln: University of Nebraska Press.

Premack, D. (1971). Catching up with common sense or two sides of a generalization: Reinforcement and punishment. In R. Glaser (Ed.), The nature of reinforcement. New York: Academic Press.

SIEGEL, S. (1956). Nonparametric statistics for the behavioral sciences. New York: McGraw-Hill.

Timberlake, W. (1980). A molar equilibrium theory of learned performance. In G. Bower (Ed.), The psychology of learning and motivation (Vol. 14). New York: Academic Press. 
Timberlake, W., \& Allison, J. (1974). Response deprivation: An empirical approach to instrumental performance. Psychological Review, 81, 146-164.

Weber, S. J., \& CooK, T. D. (1972). Subject effects in laboratory research: An examination of subject roles, demand characteristics, and valid inference. Psychological Bulletin, 77, 273-295.

\section{NOTE}

1. Full copies of the subject's instructions and the two forms of the questionnaire may be obtained from the author.

(Manuscript received for publication May 6, 1986.)

\section{Announcement}

\section{National Institute of Mental Health \\ Extramural Research Support Programs}

The National Institute of Mental Health announces the availability of a revised Extramural Research Support Programs notice, MH-86-18. This notice reflects changes in programs resulting from the recent reorganization of the Institute. It also contains the new schedule for the review of applications and an updated list of contact persons for the ongoing research programs.

Copies of the revised announcement may be requested from Anne Cooley, Extramural Policy Branch, Division of Extramural Activities, NIMH, Room 9-95 Parklawn Building, 5600 Fishers Lane, Rockville, Maryland 20857. The telephone number is: $301-443-4673$. 